Brit. Heart F., 1967, 29, 920.

\title{
Calibration of Indicator Dilution Curves in Man by the Dynamic Method
}

\author{
E. SHINEBOURNE, J. FLEMING, AND J. HAMER \\ From the Cardiac Department, St. Bartholomew's Hospital, London E.C.1
}

The original method for the measurement of cardiac output by the indicator dilution technique required the timed collection of multiple samples of arterial blood and the subsequent estimation of the concentration of indicator in each sample (Hamilton et al., 1928). The introduction of continuously recorded indicator dilution curves (Friedlich, Heimbecker, and Bing, 1950) greatly simplified the method but introduced problems of calibration. Sparling et al. (1960) described a simple method for calibrating indicator dilution curves, which avoids the need for any chemical or spectrophotometric analysis. In this "dynamic" method the indicator dilution curve from the patient is calibrated by comparison with a curve obtained in an ancillary calibration system. Evaluation of the dynamic method in a model (Emanuel and Norman, 1963) showed that flows calculated in this way agreed closely with direct measurements. Comparison of simultaneous cardiac output measurements from multiple arterial samples and from continuously recorded curves calibrated by the dynamic method showed satisfactory agreement in dogs (Emanuel et al., 1966).

The present study describes the use of the dynamic method of calibration in the repeated measurement of the cardiac output in man by the indicator dilution technique. The reliability of the method is confirmed by the demonstration that the calibration curves are reproducible when a linear recording system is used. Cardiac outputs obtained in this way are similar to measurements based on the Fick principle. A technique is described for applying the dynamic method of calibration to alinear recording systems.

\section{SubJects AND MethodS}

Repeated measurements of cardiac output were made in 27 patients with ischæmic or hypertensive heart disease.

Received February 28, 1967.
Small polyethylene catheters ${ }^{\star}$ were inserted percutaneously into the left basilic vein as far as the axilla, and into the right brachial artery for 5 to $10 \mathrm{~cm}$., under local anæsthesia. Indocyanine green ( 3 or $4 \mathrm{ml}$. of 25 to 50 $\mathrm{mg} . / 100 \mathrm{ml}$. solution) was injected into the vein using a calibrated injection device and a $20 \mathrm{ml}$. flushing syringe. Arterial blood was withdrawn through a cuvette using a $50 \mathrm{ml}$. siliconized syringe in a syringe-puller with a constant withdrawal rate (Physics Workshop, St. Bartholomew's Hospital). Dye dilution curves were obtained by two methods. In 11 subjects a Gilford densitometer (Model 103 IR) and a Servoscribe potentiometric recorder $\nmid$ were used, giving a linear response to increasing concentrations of dye. In 16 subjects the dye dilution curve was recorded with a Cambridge Mark II densitometer which had an alinear response. Blood passed through the cuvette into a hollow perspex block of $50 \mathrm{ml}$. capacity divided by an elastic membrane $\ddagger$ to prevent blood entering the withdrawal syringe. The whole system was sterilized and filled with heparinized saline before use. After each measurement the blood was returned to the patient by reversing the syringe puller. In this way many estimates of cardiac output can be made without blood loss. The part of the system that blood entered was flushed with heparinized saline after each measurement.

For calibration by the dynamic method an indicator dilution curve must be obtained in a separate system with a known flow rate. An additional component inserted between the arterial line and the cuvette allowed the injection of a small quantity of dye and its subsequent spread to produce a curve of similar amplitude to that obtained from the patient. The calibration system (Fig. 1) consisted of a short segment $(4 \mathrm{~cm}$.) of thick rubber tubing connected to a glass tube, $10 \mathrm{~cm}$. long and $1.1 \mathrm{~cm}$. in internal diameter, filled with glass beads, $3 \mathrm{~mm}$. in diameter, and with wire mesh at each end. The system was identical with that used by Emanuel et al. (1966) but the glass beads were not siliconized.

The calibration system was cleaned thoroughly after use

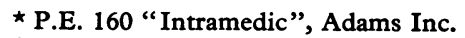

$\dagger$ Kelvin Electronics Co.

$\ddagger$ M036, Kipp and Zonen, Delft, Holland. 


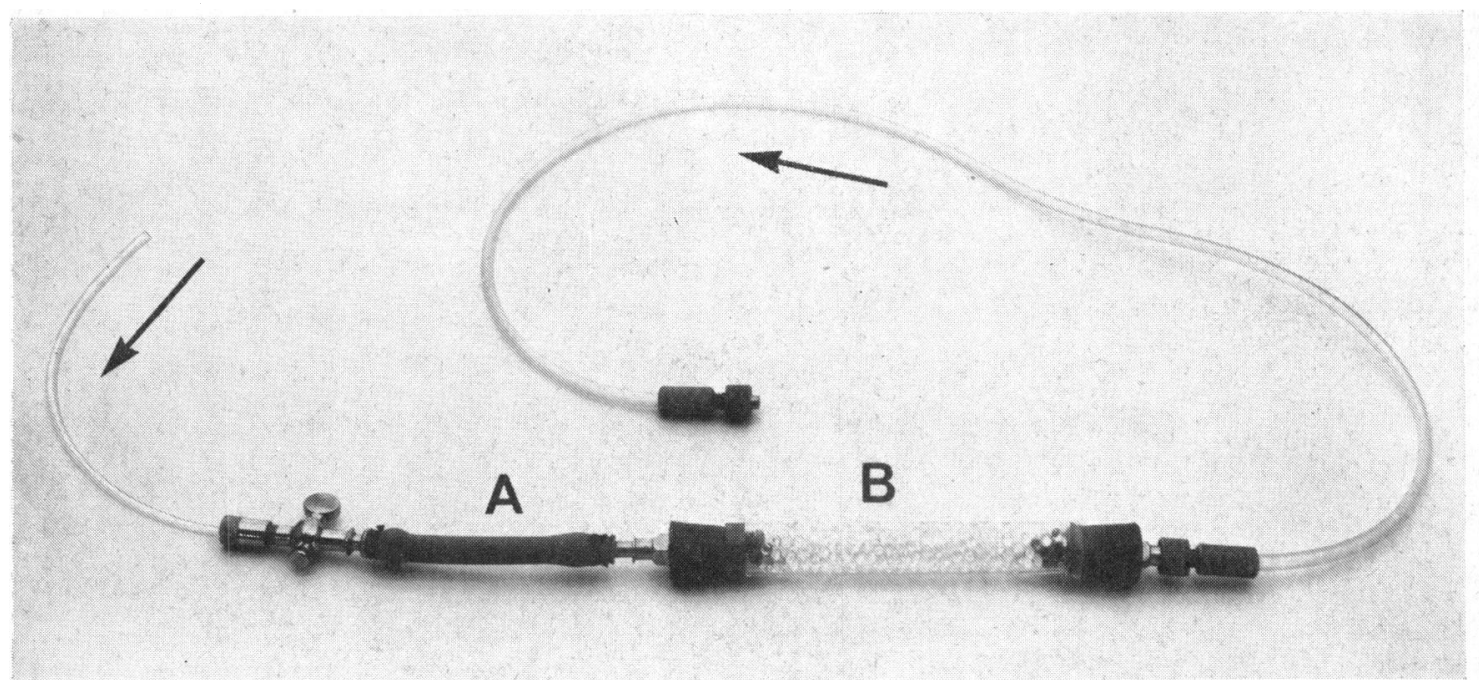

FIG. 1.-Calibration system showing thick rubber tubing for dye injection (A), glass tube with beads (B), and direction of blood flow.

and flushed overnight with a solution of hydrogen peroxide (10 vol. \%). The components were then stored in a formalin cabinet. Before each study, the system was assembled under sterile conditions, flushed, and filled with heparinized saline. Calibration was performed by drawing blood through the calibration system to remove all saline. When the baseline recorded at the cuvette was steady, a known quantity, usually 10 or 20 microlitres ( $\mu 1$.), of the dye solution used for the patient curve was injected through the rubber tubing using a $50 \mu \mathrm{l}$. Hamilton syringe. The rate of flow through the system was similar to that used for the patient curves and was measured accurately by timing the flow of 20 or $30 \mathrm{ml}$. saline into the withdrawal syringe with a stop-watch. Great care was taken to exclude air from the system as an expanding bubble may give an erroneous measurement of flow. After the calibration curve had been obtained the calibration system was disconnected and flushed with heparinized saline. The blood that had been withdrawn through the calibration system was returned to the patient in the usual way. The curve areas were measured by adding the heights of the curve at $1 \mathrm{sec}$. intervals, after the effect of recirculation on the patient curve had been eliminated by extrapolation of the initial exponential decay. Curves recorded with the Cambridge apparatus were read with the linearity correction grid provided by the manufacturer.

The cardiac output is obtained by comparing the patient and calibration indicator dilution curves. In each case the area of the curve can be measured and the amount of dye injected is known. The blood flow (Q) in the patient or in the calibration system can be derived from the ratio of the amount of dye injected (I) and the area of the curve (A):

$$
Q=I / A \text {. }
$$

As the flow in the calibration system has been measured, the flow in the patient, i.e. the cardiac output, can be obtained by comparison:

$$
\mathrm{Q}: \mathrm{Q}_{\mathrm{c}}:: \frac{\mathrm{I}}{\mathrm{A}}: \frac{\mathrm{I}_{\mathrm{c}}}{\mathrm{A}_{\mathrm{c}}},
$$

where the subscript $c$ refers to the calibration system. Therefore,

$$
\frac{\mathrm{Q}}{\mathrm{Q}_{\mathrm{c}}}=\frac{\mathrm{I}}{\mathrm{A}} \times \frac{\mathrm{A}_{\mathrm{c}}}{\mathrm{I}_{\mathrm{c}}} \text {, and } \mathrm{Q}=\mathrm{Q}_{\mathrm{c}} \times \frac{\mathrm{A}_{\mathrm{c}}}{\mathrm{I}_{\mathrm{c}}} \times \frac{\mathrm{I}}{\mathrm{A}} .
$$

As the ratios of the curve areas are used in the calculation these may be expressed in arbitrary units. Similarly, it is not necessary to know the concentration of the dye solution used. As the flow $\left(Q_{c}\right)$, amount of dye injected $\left(I_{c}\right)$, and curve area $\left(A_{c}\right)$ for the calibration system are known, the formula for the cardiac output may be simplified to $Q=K_{c} \times I / A$, where $K_{c}=Q_{c} \times A_{c} / I_{c}$, and is described as the calibration constant.

The resting cardiac output was estimated in a similar way in 10 patients with mitral or aortic valve disease during routine cardiac catheterization. The results were compared with cardiac output measurements by the Fick principle, which were obtained a few minutes after the indicator dilution curves. The oxygen content of pulmonary and brachial artery blood samples was measured by the method of Van Slyke and Neill (1924), or by calculation from saturation measurements with the Kipp Hemoreflector ${ }^{\star}$. Oxygen uptake was estimated from standard tables.

\section{RESULTS}

The reproducibility of the calibration constant $\left(\mathrm{K}_{\mathrm{c}}\right)$ was determined from paired estimations in 15 subjects, using the linear recording system (Table I and Fig. 2). There was no difference between the

\footnotetext{
* M01, Kipp and Zonen, Delft, Holland.
} 
TABLE I

DIFFERENCE BETWEEN PAIRED CALIBRATION CURVES USING LINEAR RECORDING SYSTEM

\begin{tabular}{|c|c|c|c|c|c|c|c|c|c|c|}
\hline \multirow{3}{*}{ Patient } & \multirow{2}{*}{\multicolumn{2}{|c|}{$\underset{\text { units }}{\text { Curve area }}\left(A_{c}\right)$}} & \multirow{2}{*}{\multicolumn{2}{|c|}{$\begin{array}{l}\text { Flow }\left(Q_{c}\right) \\
\text { (ml./min.) }\end{array}$}} & \multirow{2}{*}{\multicolumn{2}{|c|}{ Dye dose $\left(\mathbf{I}_{\mathrm{c}}\right)$}} & \multicolumn{3}{|c|}{ Calibration constant } & \multirow{3}{*}{$\begin{array}{l}\text { No. of inter- } \\
\text { vening output } \\
\text { measurements }\end{array}$} \\
\hline & & & & & & & \multicolumn{2}{|c|}{$\mathrm{K}_{\mathrm{c}}=\frac{\mathbf{A}_{\mathrm{c}} \times \mathbf{Q}_{\mathrm{c}}}{\mathrm{I}_{\mathrm{c}}}$} & \multirow{2}{*}{$\begin{array}{c}1 \text { st-2nd } \\
\text { as } \% \text { of } 1 \text { st }\end{array}$} & \\
\hline & 1st & 2nd & 1st & 2nd & 1st & 2nd & 1st & 2nd & & \\
\hline $\begin{array}{l}\text { E.B. } \\
\text { L.S. } \\
\text { A.P. } \\
\text { L.M. } \\
\text { A.B. } \\
\text { N.W. } \\
\text { R.V. } \\
\text { W.G. } \\
\text { H.B. } \\
\text { C.P. } \\
\text { J.W. } \\
\text { L.S. } \\
\text { F.T. } \\
\text { M.L. } \\
\text { R.B. }\end{array}$ & $\begin{array}{l}410 \\
280 \\
630 \\
580 \\
370 \\
310 \\
540 \\
520 \\
470 \\
550 \\
590 \\
560 \\
430 \\
240 \\
280\end{array}$ & $\begin{array}{l}420 \\
330 \\
620 \\
350 \\
350 \\
320 \\
600 \\
510 \\
440 \\
560 \\
630 \\
560 \\
430 \\
380 \\
230\end{array}$ & $\begin{array}{l}34.5 \\
40.0 \\
33.5 \\
19.5 \\
32.0 \\
36.0 \\
33.0 \\
34.5 \\
42.5 \\
33.5 \\
36.5 \\
34.0 \\
42.5 \\
35.5 \\
33.5\end{array}$ & $\begin{array}{l}34.5 \\
32.5 \\
35.5 \\
26.0 \\
33.5 \\
34.5 \\
29.0 \\
37.0 \\
44.5 \\
35.0 \\
33.5 \\
34.5 \\
39.0 \\
22.5 \\
39.5\end{array}$ & $\begin{array}{l}20 \\
20 \\
20 \\
20 \\
20 \\
10 \\
20 \\
15 \\
20 \\
20 \\
20 \\
20 \\
20 \\
20 \\
20\end{array}$ & $\begin{array}{l}20 \\
20 \\
20 \\
15 \\
20 \\
10 \\
20 \\
15 \\
20 \\
20 \\
20 \\
20 \\
20 \\
20 \\
20\end{array}$ & $\begin{array}{r}720 \\
550 \\
1100 \\
570 \\
590 \\
1110 \\
900 \\
1190 \\
990 \\
910 \\
1070 \\
950 \\
910 \\
420 \\
470\end{array}$ & $\begin{array}{r}730 \\
540 \\
1080 \\
610 \\
590 \\
1110 \\
880 \\
1250 \\
920 \\
990 \\
1050 \\
960 \\
840 \\
430 \\
450\end{array}$ & $\begin{array}{r}-2 \\
+1 \\
+2 \\
-8 \\
0 \\
0 \\
+2 \\
-5 \\
+7 \\
-9 \\
+3 \\
-1 \\
+8 \\
-2 \\
+4\end{array}$ & $\begin{array}{l}0 \\
0 \\
0 \\
0 \\
0 \\
0 \\
6 \\
6 \\
4 \\
2 \\
2 \\
3 \\
6 \\
3 \\
3\end{array}$ \\
\hline
\end{tabular}

average values for the first and second estimations in each pair, and the percentage error varied from -9 to +8 per cent (SD $4 \%$ ). In 9 of these subjects a number of cardiac output measurements intervened between the calibration curves (Fig. 2) but there was no difference in the findings under these circumstances. When the alinear recording system was used, similar agreement was found between pairs of calibration curves in 10 comparisons from 7 subjects when there was no change in the background concentration of dye between the measure-

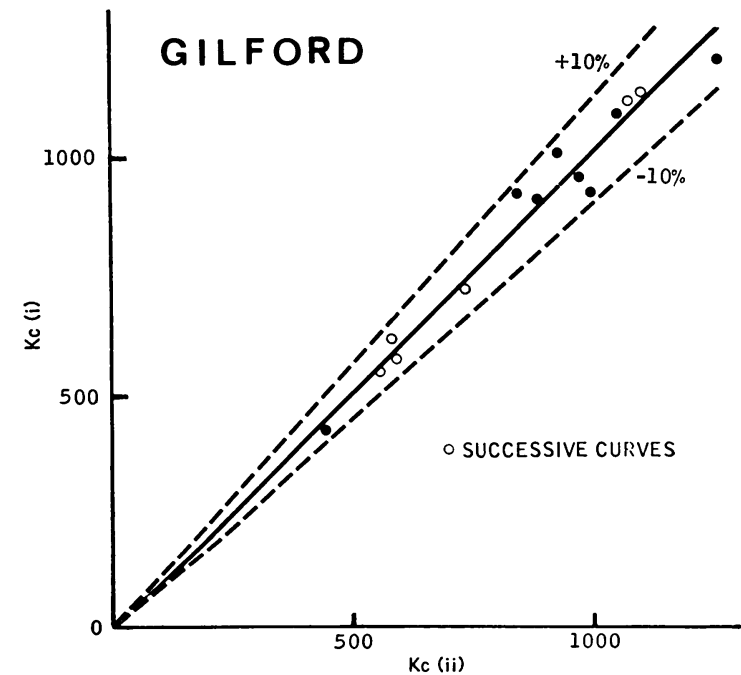

FIG. 2.-Comparison of the calibration constants $\left(\mathbf{K}_{\mathrm{c}}\right)$ in 15 paired estimations using a linear system. The solid circles indicate pairs of calibration constants separated by cardiac output measurements. The open circles indicate constants with no intervening measurements. ments (Table II and Fig. 3). The difference between the average values for the first and second estimations in each pair was negligible. The percentage error varied from -10 to +12 per cent (SD 6\%). However, when several cardiac output measurements were made between the calibration curves, so that the background concentration of dye increased, there was a consistent reduction in the calibration constant $\left(\mathrm{K}_{\mathrm{c}}\right)$ from the second curve. Table III shows 14 such comparisons in 9 subjects with between 2 and 6 cardiac output measurements separating the calibration curves. In 6 instances the mean of a pair of calibration measurements was used. There was on average nearly a 10 per cent reduction in the second calibration constant (Fig. 3).

Twelve cardiac output measurements by the Fick method in 10 subjects showed considerable agreement with the indicator dilution measurements over a wide range (from 2.6 to $6 \cdot 21$./min.) (Fig. 4 and Table IV). In this part of the study only the linear recording system was used. On average the indicator dilution measurements were 3 per cent greater than the Fick measurements (SD 15\%, r = 0.96).

\section{Discussion}

The close agreement between pairs of calibration constants (Fig. 2) when a linear recording system (Gilford) is used is an indication of the reproducibility of the calibration curves, and shows that the flow rate and mixing properties of the calibration system are satisfactory. The method has the advantage that the calibration is obtained with freshly withdrawn blood from the subject being studied, under similar flow conditions to the indicator dilution curve from the patient. Errors due to 
Calibration of Indicator Dilution Curves in Man by Dynamic Method

TABLE II

DIFFERENCE BETWEEN PAIRED CALIBRATION CURVES WITHOUT INTERVENING OUTPUT MEASUREMENTS USING ALINEAR RECORDING SYSTEM

\begin{tabular}{|c|c|c|c|c|c|c|c|c|c|}
\hline \multirow{3}{*}{ Patient } & \multirow{2}{*}{\multicolumn{2}{|c|}{$\underset{\text { (units) }}{\text { Curve area }}\left(\mathbf{A}_{\mathbf{c}}\right)$}} & \multirow{2}{*}{\multicolumn{2}{|c|}{$\begin{array}{l}\text { Flow }\left(Q_{c}\right) \\
(\mathrm{ml} . / \mathrm{min} .)\end{array}$}} & \multirow{2}{*}{\multicolumn{2}{|c|}{ Dye dose $\left(\mathbf{I}_{\mathrm{c}}\right)$}} & \multicolumn{3}{|c|}{ Calibration constant } \\
\hline & & & & & & & \multicolumn{2}{|c|}{$\mathrm{K}_{\mathrm{c}}=\frac{\mathbf{A}_{\mathrm{c}} \times \mathbf{Q}_{\mathrm{c}}}{\mathbf{I}_{\mathrm{c}}}$} & \multirow{2}{*}{$\begin{array}{c}1 \mathrm{st}-2 \mathrm{nd} \\
\text { as } \% \text { of } 1 \mathrm{st}\end{array}$} \\
\hline & 1st & 2nd & $1 \mathrm{st}$ & 2nd & $1 \mathrm{st}$ & 2nd & $1 \mathrm{st}$ & 2nd & \\
\hline $\begin{array}{l}\text { L.P. } \\
\text { J.S. } \\
\text { A.W. } \\
\text { J.M. } \\
\text { J.M. } \\
\text { R.L. } \\
\text { J.E. } \\
\text { J.E. } \\
\text { J.E. } \\
\text { J.S. }\end{array}$ & $\begin{array}{r}880 \\
570 \\
960 \\
1260 \\
1240 \\
450 \\
490 \\
570 \\
630 \\
1160\end{array}$ & $\begin{array}{r}780 \\
620 \\
850 \\
1200 \\
1220 \\
410 \\
500 \\
950 \\
740 \\
1130\end{array}$ & $\begin{array}{l}26.5 \\
30.0 \\
40.0 \\
32.5 \\
34.5 \\
36.0 \\
32.0 \\
37.5 \\
37.5 \\
39.0\end{array}$ & $\begin{array}{l}31 \cdot 0 \\
30.0 \\
40.0 \\
32.5 \\
34.5 \\
40.0 \\
34.5 \\
22.0 \\
34.5 \\
38.0\end{array}$ & $\begin{array}{l}20 \\
10 \\
20 \\
20 \\
20 \\
20 \\
20 \\
20 \\
20 \\
20\end{array}$ & $\begin{array}{l}20 \\
10 \\
20 \\
20 \\
20 \\
20 \\
20 \\
20 \\
20 \\
20\end{array}$ & $\begin{array}{r}1180 \\
1710 \\
1930 \\
2040 \\
2130 \\
810 \\
780 \\
1080 \\
1170 \\
2260\end{array}$ & $\begin{array}{r}1180 \\
1850 \\
1700 \\
1940 \\
2100 \\
820 \\
870 \\
1060 \\
1270 \\
2140\end{array}$ & $\begin{array}{r}0 \\
-8 \\
+12 \\
+5 \\
+1 \\
-1 \\
-10 \\
+2 \\
-8 \\
+5\end{array}$ \\
\hline
\end{tabular}

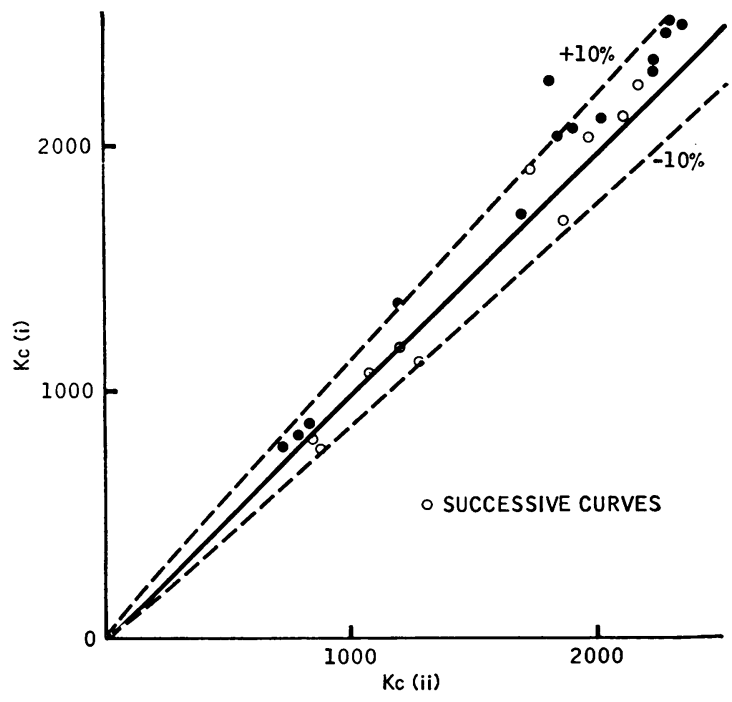

FIG. 3.-Comparison of the calibration constants $\left(\mathrm{K}_{\mathrm{c}}\right)$ in 24 paired estimations using an alinear system. The solid circles indicate pairs of calibration constants separated by cardiac output measurements. The open circles indicate constants with no intervening measurements.

TABLE III

DIFFERENCE BETWEEN CALIBRATION CURVES BEFORE AND AFTER SERIES OF CARDIAC OUPUT MEASUREMENTS USING ALINEAR RECORDING SYSTEM

\begin{tabular}{|c|c|c|c|c|c|c|c|c|c|c|}
\hline \multirow{3}{*}{ Patient } & \multirow{2}{*}{\multicolumn{2}{|c|}{$\underset{\text { (units) }}{\text { Curve area }}\left(\mathbf{A}_{\mathbf{c}}\right)$}} & \multirow{2}{*}{\multicolumn{2}{|c|}{$\begin{array}{l}\text { Flow }\left(Q_{c}\right) \\
(\mathrm{ml} . / \mathrm{min} .)\end{array}$}} & \multirow{2}{*}{\multicolumn{2}{|c|}{ Dye dose $\left(I_{c}\right)$}} & \multicolumn{3}{|c|}{ Calibration constant } & \multirow{3}{*}{$\begin{array}{l}\text { No. of inter- } \\
\text { vening output } \\
\text { measurements }\end{array}$} \\
\hline & & & & & & & \multicolumn{2}{|c|}{$\mathbf{K}_{\mathrm{c}}=\frac{\mathbf{A}_{\mathbf{c}} \times \mathbf{Q}_{\mathrm{c}}}{\mathbf{I}_{\mathbf{c}}}$} & \multirow{2}{*}{$\begin{array}{c}1 s t-2 \text { nd } \\
\text { as } \% \text { of } 1 s t\end{array}$} & \\
\hline & 1st & 2nd & 1st & 2nd & 1 st & 2nd & 1st & 2nd & & \\
\hline $\begin{array}{l}\text { L.P. } \\
\text { R.P. } \\
\text { R.P. } \\
\text { H.R. } \\
\text { H.R. } \\
\text { A.W. } \\
\text { P.H. } \\
\text { J.M. } \\
\text { R.L. } \\
\text { R.L. } \\
\text { R.L. } \\
\text { C.S. } \\
\text { J.S. } \\
\text { J.S. }\end{array}$ & $\begin{array}{r}780 \\
840 \\
760 \\
1010 \\
980 \\
1090 \\
720 \\
1250 \\
430 \\
430 \\
470 \\
1250 \\
620 \\
1120\end{array}$ & $\begin{array}{r}830 \\
760 \\
1190 \\
840 \\
930 \\
908 \\
780 \\
1230 \\
430 \\
470 \\
360 \\
1050 \\
1120 \\
1150\end{array}$ & $\begin{array}{l}25.0 \\
30.0 \\
46.5 \\
34.5 \\
43.0 \\
37.5 \\
48.0 \\
34.5 \\
40.0 \\
38.0 \\
33.0 \\
39.5 \\
40.0 \\
41.5\end{array}$ & $\begin{array}{l}29 \cdot 0 \\
46 \cdot 5 \\
30 \cdot 0 \\
40 \cdot 0 \\
40 \cdot 5 \\
40 \cdot 0 \\
40 \cdot 0 \\
32.5 \\
38 \cdot 0 \\
33 \cdot 0 \\
40 \cdot 0 \\
43 \cdot 0 \\
41.5 \\
38.5\end{array}$ & $\begin{array}{l}20 \\
10 \\
10 \\
20 \\
20 \\
20 \\
20 \\
20 \\
20 \\
20 \\
20 \\
20 \\
10 \\
20\end{array}$ & $\begin{array}{l}20 \\
10 \\
10 \\
20 \\
20 \\
20 \\
20 \\
20 \\
20 \\
20 \\
20 \\
20 \\
20 \\
20\end{array}$ & $\begin{array}{c}1360 \\
2510 \\
2280 \\
1730 \\
2090 \\
2050 \\
1740 \\
2140 \\
860 \\
810 \star \\
780 \\
2480 \\
2500 \\
2320\end{array}$ & $\begin{array}{l}1180^{\star} \\
2280 \\
1780 \\
1680 \\
1880 \\
1810^{\star} \\
1660 \\
1990^{\star} \\
810^{\star} \\
780 \\
720 \\
2260 \\
2320 \\
2200^{\star}\end{array}$ & $\begin{array}{l}+13 \\
+9 \\
+18 \\
+4 \\
+10 \\
+12 \\
+5 \\
+7 \\
+5 \\
+4 \\
+8 \\
+9 \\
+7 \\
+5\end{array}$ & $\begin{array}{l}6 \\
4 \\
4 \\
4 \\
3 \\
3 \\
4 \\
3 \\
4 \\
3 \\
3 \\
4 \\
2 \\
4\end{array}$ \\
\hline
\end{tabular}

* Mean of two determinations (see Table II). 


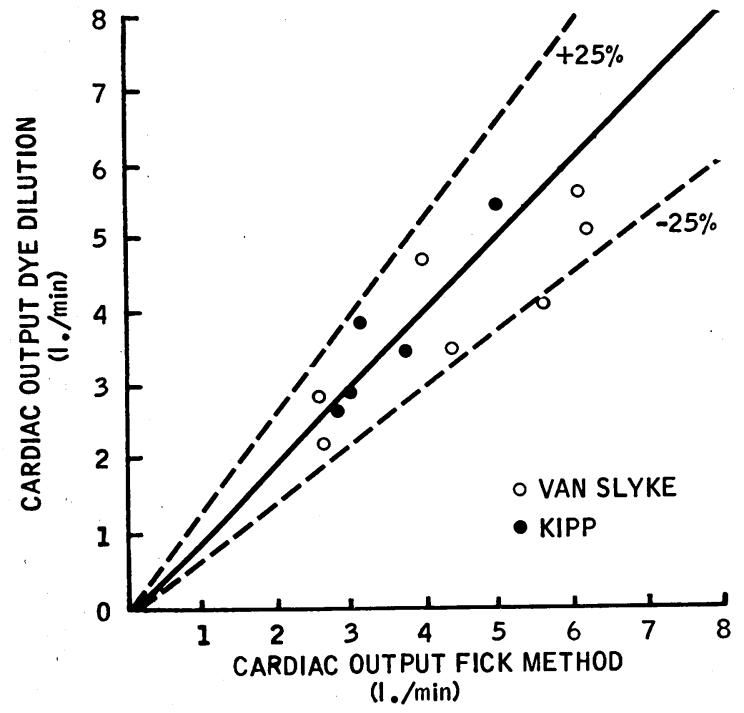

Fig. 4. Twelve comparisons from ten subjects of cardiac output measurements by the Fick principle and by indicator dilution using the dynamic method of calibration.

changes in the properties of the blood are therefore avoided. The residual errors in the method are due to inaccuracies in drawing up small volumes of dye solution with the Hamilton syringe, in measuring the area of the calibration curve which tends to be of shorter duration than the patient curve, and in the estimation of the flow rate in the calibration system. Although the syringe-puller has, nominally, a constant withdrawal speed for a given setting of the controls, there are small variations due to changes in the resistance to flow so that separate measurement of the flow for each curve is desirable. Variations due to changes in the supply voltage or to the motor warming-up can be minimized by appropriate precautions. Changes in the flow rate in the calibration

TABLE IV

COMPARISON OF FICK AND DYNAMIC METHODS (SUCCESSIVE CARDIAC OUTPUTS IN 12 EXPERIMENTS)

\begin{tabular}{|c|c|c|c|}
\hline Patient & $\begin{array}{l}\text { Cardiac output } \\
\text { Fick (A) } \\
\text { (1./min.) }\end{array}$ & $\begin{array}{l}\text { Cardiac output } \\
\text { Dye (B) } \\
\text { (l./min.) }\end{array}$ & $\begin{array}{c}\text { Difference A-B } \\
\text { as } \% \text { of } \mathrm{A}\end{array}$ \\
\hline $\begin{array}{l}\text { E.S. } \\
\text { M.W. } \\
\text { J.W. } \\
\text { E.L. } \\
\text { H.B. } \\
\text { E.Q. } \\
\text { C.P. } \\
\text { F.H. } \\
\text { M.L. } \\
\text { M.L. } \\
\text { M.L. } \\
\text { B.S. }\end{array}$ & $\begin{array}{l}2.6 \\
2.6 \\
5.0 \\
6.1 \\
5.6 \\
6.2 \\
4 \cdot 3 \\
4.0 \\
3.1 \\
2.7 \\
3.0 \\
3.7\end{array}$ & $\begin{array}{l}2 \cdot 2 \\
2.8 \\
5.4 \\
5.6 \\
4.1 \\
5.1 \\
3.5 \\
4 \cdot 7 \\
3.8 \\
2.7 \\
2.9 \\
3.4\end{array}$ & $\begin{array}{r}13 \\
-9 \\
-10 \\
8 \\
27 \\
18 \\
18 \\
-19 \\
-23 \\
0 \\
2 \\
7\end{array}$ \\
\hline
\end{tabular}

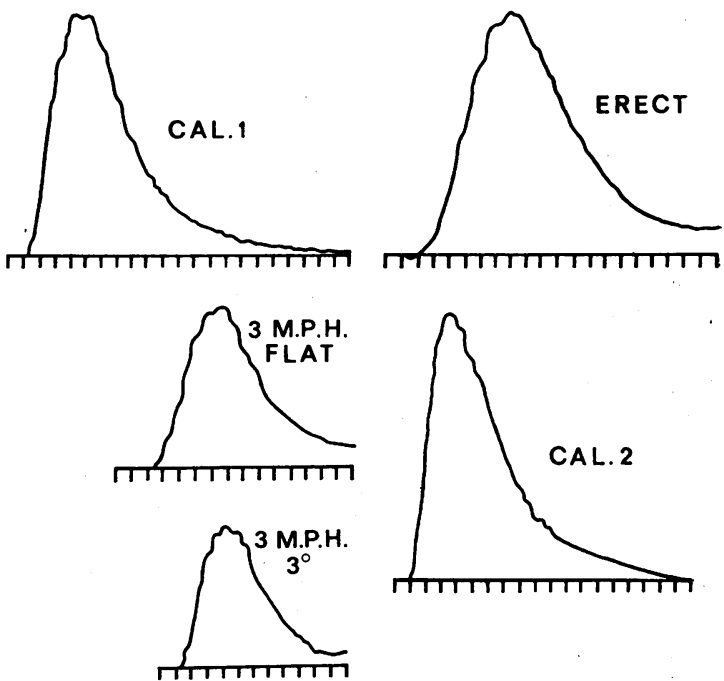

FIG. 5.-Calibration curves obtained in patient H.B. before and after a series of cardiac output measurements at graded work loads (time interval in seconds).

system $\left(Q_{c}\right)$ or in the volume of dye injected $\left(I_{c}\right)$ do not in themselves produce any error in the calibration constant $\left(\mathrm{K}_{\mathrm{c}}\right)$ provided they are measured accurately. Any variation in flow or in dye injected leads to a corresponding change in dye curve area $\left(A_{c}\right)$, so that the calibration constant $\left(K_{c}=Q_{c} \times\right.$ $\left.A_{c} / I_{c}\right)$ is unaffected. The method has proved satisfactory in use and no local or general complications have occurred.

The absence of any systematic change in the calibration curves after a number of cardiac output measurements with the linear recording system (Gilford) indicates that a separate calibration curve is not necessary for each determination of the cardiac output. It is our present practice to obtain calibration curves before and after a series of 3 or 4 cardiac output measurements (Fig. 5). The mean calibration constant is then used to calculate the cardiac outputs from the formula $Q=K_{c} \times I / A$.

The reproducibility of the calibration constants with the alinear recording system (Cambridge) when there was no change in the background concentration of dye (Table II, Fig. 3) indicates that the dynamic method can also be used with apparatus of this type. The reduction in the calibration constant after a number of cardiac output estimations with the Cambridge apparatus is not unexpected and indicates an increasing alinearity of response which must also affect the patient curves. It is not possible to predict the changes in background dye concentration from the amount of dye injected and the 
size of the patient, owing to the variable rate of excretion and the different intervals between the measurements. For strict accuracy a calibration curve immediately before each cardiac output estimation is needed, but we have found that a calibration before and after a series of 3 or 4 measurements gives satisfactory results. Appropriate values of the calibration constant for each curve can be obtained by interpolation. It is evident from our findings that the linearity correction grid provided for the Cambridge apparatus does not give a complete correction when the background level of dye is very high. As pointed out by Zijlstra et al. (1965), the dynamic method can be used in an alinear system if the height of the calibration curve is similar to that of the patient curve. The alinearity of the vertical scale is then the same for the two curves, and as the ratio of the area measurements is used in the calculation no correction is necessary. We have applied this principle when using the Cambridge apparatus by adjusting the amount of dye injected for the calibration curve.

A close agreement between Fick and indicator dilution measurements of cardiac output is not to be expected on theoretical grounds (Taylor, 1966). In particular, the indicator dilution method is more influenced by rapid variations in cardiac output as the measurements are completed in a few seconds. Our comparisons were not made with simultaneous measurements and under the circumstances the degree of agreement is satisfactory. Although there is considerable scatter, the agreement of the mean values for the cardiac output by the two methods is close. These findings are further evidence of the accuracy of the dynamic method of calibration of indicator dilution curves.

\section{Conclusions}

In our view the dynamic method of calibration is a considerable advance in the application of indicator dilution techniques. It allows rapid and accurate calibration of indicator dilution curves using the same methods of measurement as for the curve from the patient. The method is suitable for the repeated measurement of the cardiac output and may be used with automatic measurement of curve areas (Hamer et al., 1966), which further increases the speed and convenience of the technique. It may also be applied successfully to alinear recording systems.

\section{SUMMARY}

The dynamic method of calibration of indicator dilution curves is based on comparison of the curve from the patient with a similar curve from an ancillary system in which the flow is known. The method has previously been shown to give satisfactory results in a model circulation and for the measurement of the cardiac output in dogs.

Details of the use of the dynamic method in man are described. Close agreement between successive calibration curves indicates that the method is satisfactory. When a linear recording system is used there is no change in the calibration curve after injections of indicator. The application of the method to alinear recording systems is described.

Reasonable agreement is shown between cardiac output measurements based on the Fick principle and from indicator dilution curves calibrated by the dynamic method.

It is concluded that the dynamic method is an accurate and convenient way to calibrate indicator dilution curves for the repeated measurement of the cardiac output in man.

\section{REFERENCES}

Emanuel, R., Hamer, J., Chiang B.-N., Norman, J., and Manders, J. (1966). A dynamic method for the calibration of dye dilution curves in a physiological system. Brit. Heart f., 28, 143.

- , and Norman, J. (1963). Evaluation of a dynamic method for calibration of dye dilution curves. Brit. Heart f., 25, 308.

Friedlich, A., Heimbecker, R., and Bing, R. J. (1950). A device for continuous recording of concentration of Evans Blue dye in whole blood and its application to determination of cardiac output. F. appl. Physiol., 3, 12 .

Hamer, J., Emanuel, R., Norman, J., and Burgess, M. (1966). Use of a computer in the calibration of dye dilution curves by a dynamic method. Brit. Heart F., 28, 147.

Hamilton, W. F., Moore, J. W., Kinsman, J. M., and Spurling, R. G. (1928). Simultaneous determination of the greater and lesser circulation times, of the mean velocity of blood flow through the heart and lungs, of the cardiac output and an approximation of the amount of blood actively circulating in the heart and lungs. Amer. F. Physiol., 85, 377.

Sparling, C. M., Mook, G. A., Nieveen, J., Van der Slikke, L. B., and Zijlstra, W. G. (1960). Calibration of dye dilution curves for calculating cardiac output and central blood volume. In C. R. 3e Congrès Européen de Cardiologie, Rome. (Acta Tertii Europæi de Cordis Scientia Conventus, Romæ.) Pars altera A. p. 595.

Taylor, S. H. (1966). Measurement of the cardiac output in man. In Measurement in Therapeutic Assessment. Proc. roy. Soc. Med., 59, Suppl., p. 35.

Van Slyke, D. D., and Neill, J. M. (1924). The determination of gases in blood and other solutions by vacuum extraction and manometric measurement. $\mathcal{f}$. biol. Chem., 61, 523.

Zijlstra, W. G., Mook, G. A., Ten Hoor, F., and Kruizinga, K. (1965). Recording of dye dilution curves by reflectometry in red or infra-red light. Shandon Instrument Application No. 14. Shandon Scientific Co. Ltd., London. 